\title{
Article \\ Stroke Aetiology and Collateral Status in Acute Ischemic Stroke Patients Receiving Reperfusion Therapy-A Meta-Analysis
}

\author{
Akansha Sinha ${ }^{1,2}$, Peter Stanwell ${ }^{3} \mathbb{D}$, Roy G. Beran ${ }^{1,2,4,5,6,7}$, Zeljka Calic ${ }^{1,2,5}$, Murray C. Killingsworth ${ }^{1,2,4,8}{ }^{\mathbb{D}}$ \\ and Sonu M. M. Bhaskar 1,4,5,*iD
}

1 Neurovascular Imaging Laboratory, Clinical Sciences Stream, Ingham Institute for Applied Medical Research, Sydney, NSW 2170, Australia; akansha.sinha@student.unsw.edu.au (A.S.); roy.beran@unsw.edu.au (R.G.B.); Zeljka.Calic@health.nsw.gov.au (Z.C.); Murray.Killingsworth@health.nsw.gov.au (M.C.K.)

2 South-Western Sydney Clinical School, University of New South Wales (UNSW), Sydney, NSW 2170, Australia

3 School of Health Sciences, University of Newcastle, Callaghan, Newcastle, NSW 2308, Australia; peter.stanwell@newcastle.edu.au

4 NSW Brain Clot Bank, NSW Health Pathology, Sydney, NSW 2170, Australia

5 Department of Neurology and Neurophysiology, Liverpool Hospital and South-Western Sydney Local Health District, Sydney, NSW 2170, Australia

6 Medical School, Griffith University, Gold Coast, QLD 4222, Australia

7 Faculty of Sociology, Sechenov Moscow First State University, 119991 Moscow, Russia

8 Correlative Microscopy Facility, Department of Anatomical Pathology, NSW Health Pathology, Liverpool, NSW 2170, Australia

* Correspondence: Sonu.Bhaskar@reprogramglobal.org; Tel.: +61-(02)-873-89179

check for updates

Citation: Sinha, A.; Stanwell, P.; Beran, R.G.; Calic, Z.; Killingsworth, M.C.; Bhaskar, S.M.M. Stroke Aetiology and Collateral Status in Acute Ischemic Stroke Patients Receiving Reperfusion Therapy-A Meta-Analysis. Neurol. Int. 2021, 13, 608-621. https://doi.org/10.3390/ neurolint13040060

Academic Editor: Tibor Hortobagyi

Received: 29 September 2021

Accepted: 15 November 2021

Published: 16 November 2021

Publisher's Note: MDPI stays neutral with regard to jurisdictional claims in published maps and institutional affiliations.

Copyright: (c) 2021 by the authors. Licensee MDPI, Basel, Switzerland. This article is an open access article distributed under the terms and conditions of the Creative Commons Attribution (CC BY) license (https:// creativecommons.org/licenses/by/ $4.0 /)$.
Abstract: Background: The interplay between collateral status and stroke aetiology may be crucial in the evaluation and management of acute ischemic stroke (AIS). Our understanding of this relationship and its level of association remains sub-optimal. This study sought to examine the association of pre-intervention collateral status with stroke aetiology, specifically large artery atherosclerosis (LAA) and cardio-embolism (CE), in AIS patients receiving reperfusion therapy, by performing a meta-analysis. Methods: Relevant search terms were explored on Medline/PubMed, Embase and Cochrane databases. Studies were included using the following inclusion criteria: (a) patients aged 18 or above; (b) AIS patients; (c) patients receiving reperfusion therapy; (d) total cohort size of $>20$, and (e) qualitative or quantitative assessment of pre-intervention collateral status on imaging using a grading scale. Random-effects meta-analysis was performed to investigate the association of aetiology with pre-intervention collateral status, and forest plots of risk ratio (RR) were generated. Results: A meta-analysis was conducted on seven studies, with a cumulative cohort of 1235 patients, to assess the association of pre-intervention collateral status with stroke aetiology. Patients with LAA were associated significantly with an increased rate of good collaterals (RR 1.24; 95\% CI 1.04-1.50; $p=0.020, \mathrm{z}=2.33$ ). Contrarily, CE aetiology was associated significantly with a decreased rate of good collaterals (RR 0.83; 95\% CI 0.71-0.98; $p=0.027, z=-2.213$ ). Conclusions: This study demonstrates that, in AIS patients receiving reperfusion therapy, LAA and CE aetiologies are associated significantly with collateral status.

Keywords: collaterals; stroke; cerebrovascular disease; reperfusion therapy; aetiology; cardiovascular disease; neuroimaging

\section{Introduction}

Pre-intervention cerebral collateral status is an important consideration in the acute ischemic stroke (AIS) workup [1]. A crucial factor that impacts collateral recruitment is the underlying stroke aetiology [2]. AIS patients with underlying large artery atherosclerosis (LAA) aetiology have better pre-intervention collateral status-enhancing the potential to achieve improved clinical outcomes with reperfusion therapy $[3,4]$. In LAA, there 
is significantly increased shear pressure in cerebral vessels which promotes collateral formation [5]. Additionally, LAA is also linked to chronic cerebral hypoperfusion [2]. Chronic hypoperfusion may cause parenchyma to develop resilience to AIS. AIS with an embolic origin, such as cardio-embolic (CE) stroke secondary to atrial fibrillation, tends to cause sudden ischaemia. The delineation of the relationship of stroke aetiology with collateral status/recruitment is clinically relevant from a stroke diagnostic and prognostic standpoint and, hence, can assist in AIS clinical decision making.

The current clinical assessment of stroke harnesses standardised methods, such as Trial of Org 10172 in Acute Stroke Treatment (TOAST), and Causative Classification of Stroke (CCS), to delineate the underlying aetiology [6]. These methods remain suboptimal and further avenues to refine aetiology assessment in stroke patients could be useful. This study sought to investigate the association of stroke aetiology, LAA vs. CE, with pre-intervention collateral status (good vs. poor) in AIS patients receiving reperfusion therapy (RT), specifically systemic thrombolysis (using tissue plasminogen activator (tPA)) and/or endovascular thrombectomy (EVT), by performing a meta-analysis.

The underlying question was, in AIS patients receiving RT:

Is stroke aetiology, LAA or CE, associated with pre-intervention collateral status?

\section{Materials and Methods}

\subsection{Literature Search: Identification and Selection of Studies}

A Preferred Reporting Items for Systematic Reviews and Meta-Analyses (PRISMA) diagram explaining the search strategy, as well as details regarding the included studies, can be found in Figure 1. The protocol in this study adheres to the STARD-2015 guidelines (Supplemental Table S2), and the Meta-analysis Of Observational Studies in Epidemiology (MOOSE) checklist (Supplemental Table S3) [7]. Studies published in the English language investigating the impact of pre-intervention collateral status on AIS patients receiving RT with either LAA or CE as their stroke aetiology were reviewed on PubMed/Medline, Embase and the Cochrane Central Register of Controlled Trials for the period from January 2005 to June 2021. The search terms included: cerebral collateral, antegrade collateral, retrograde collateral and ischemic stroke, AIS, acute ischemic stroke anterior circulation, large vessel occlusion and reperfusion, endovascular treatment, tPA, EVT, clot retrieval, systemic thrombolysis and mechanical thrombectomy. The detailed search strategy can be found in the Supplementary Information (Search Terms). The following filters were applied: full text, English language, humans, and adults ( $>18$ years) for the previously stated time frame. 


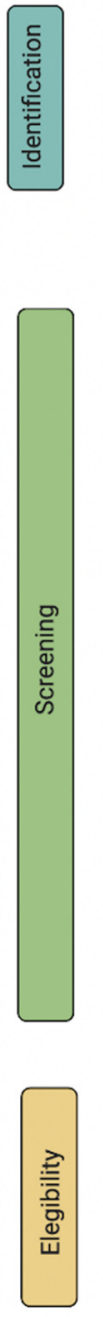

Records identified through database search $(n=4831)$

- Medline $(n=2960)$

- Embase $(n=1688)$

- Cochrane central register of controlled trials $(n=183)$

Additional records

identified through

other sources

$(n=32)$
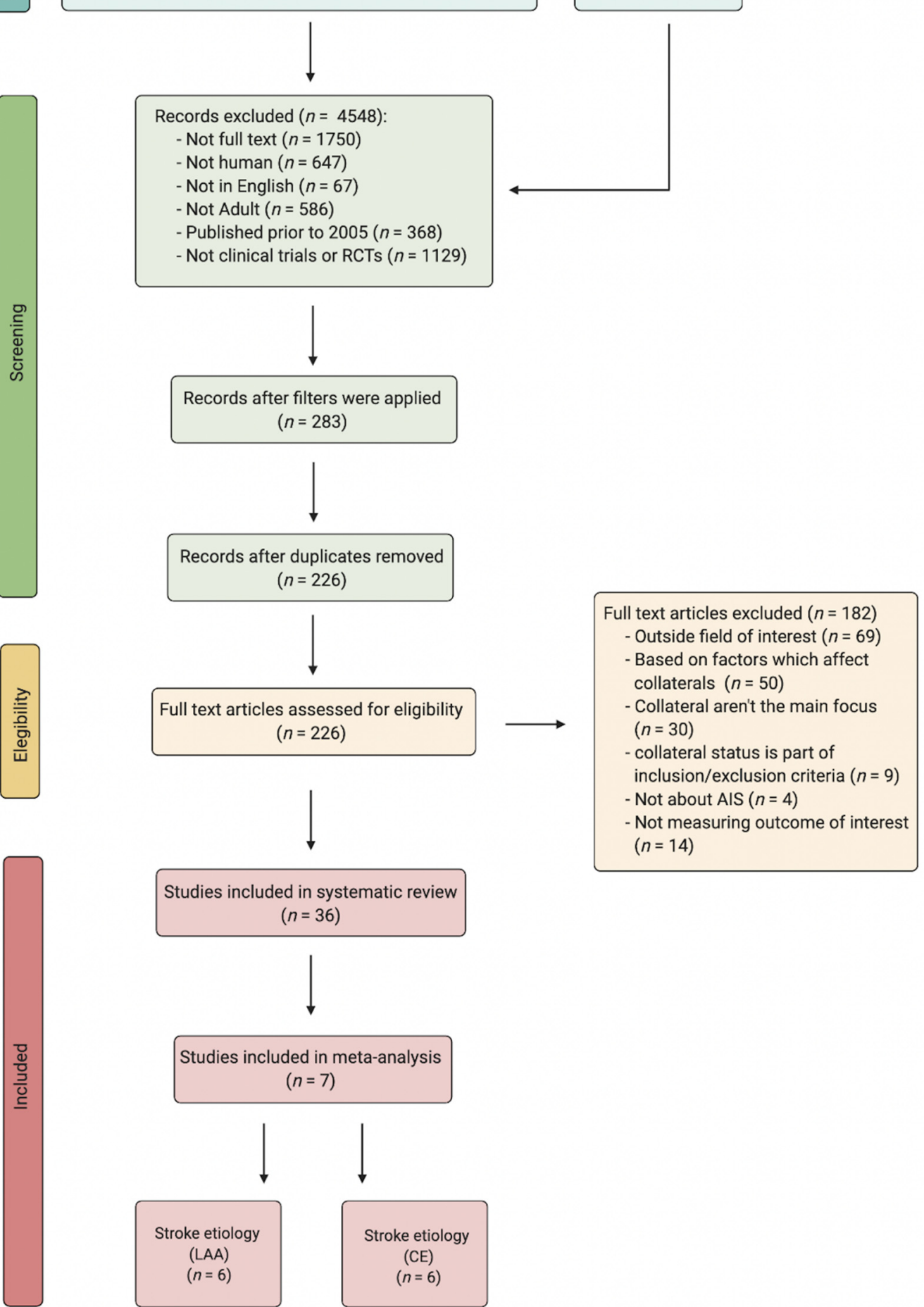

Studies included in systematic review $(n=36)$
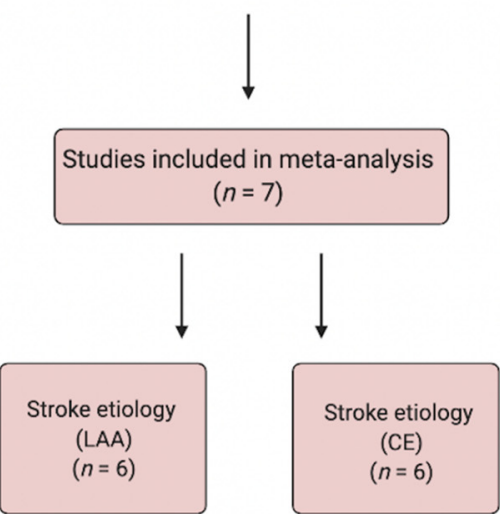

Figure 1. PRISMA flowchart detailing the process of finding and selecting studies for the metaanalysis. Abbreviations: RCT, randomised controlled trials; AIS, acute ischaemic stroke; LAA, large artery atherosclerosis; $\mathrm{CE}$, cardio-embolism.

\subsection{Inclusion and Exclusion Criteria}

The following inclusion criteria were applied: (a) patients aged > 18; (b) AIS patients; (c) patients receiving reperfusion therapy-either EVT and/or tPA; (d) total cohort size of 
$>20$, and (e) qualitative or quantitative assessment of pre-intervention collateral status on imaging using a grading scale. An outline of pre-intervention collateral grading scales, used by the included studies, is provided (Table 1). The following exclusion criteria were applied: (a) animal studies; (b) duplicated publications; (c) full-text article not available; (d) systematic review, meta-analysis, case conference summary; (e) texts in a language other than English and (f) data not stratified, according to the grading of pre-intervention collateral status (poor vs. good) and stroke aetiology (LAA vs. CE).

\subsection{Data Extraction}

The titles and abstracts of studies selected from the literature search were screened for their eligibility in Endnote by two reviewers. All remaining articles were screened thoroughly to ensure they fitted within the eligibility criteria. The references of all included studies were screened for any additional studies that could be included. Any disagreement was resolved by consensus-based discussion. The following data were extracted from all included studies: (a) study details: author, title, year and country of publication; (b) patient demographics: cohort size in treatment (good collaterals) and control (poor collateral) groups, age and co-morbidities/risk factors; (c) pre-intervention collateral status (good or poor); (d) stroke aetiology of LAA or CE. All included studies dichotomised their patients into groups of good or poor collaterals based on their pre-intervention collateral status. Stroke aetiology was determined based on clinical assessment and/or the assessment of aetiology using TOAST or CCS classification. 
Table 1. Clinical characteristics of studies included in the meta-analysis.

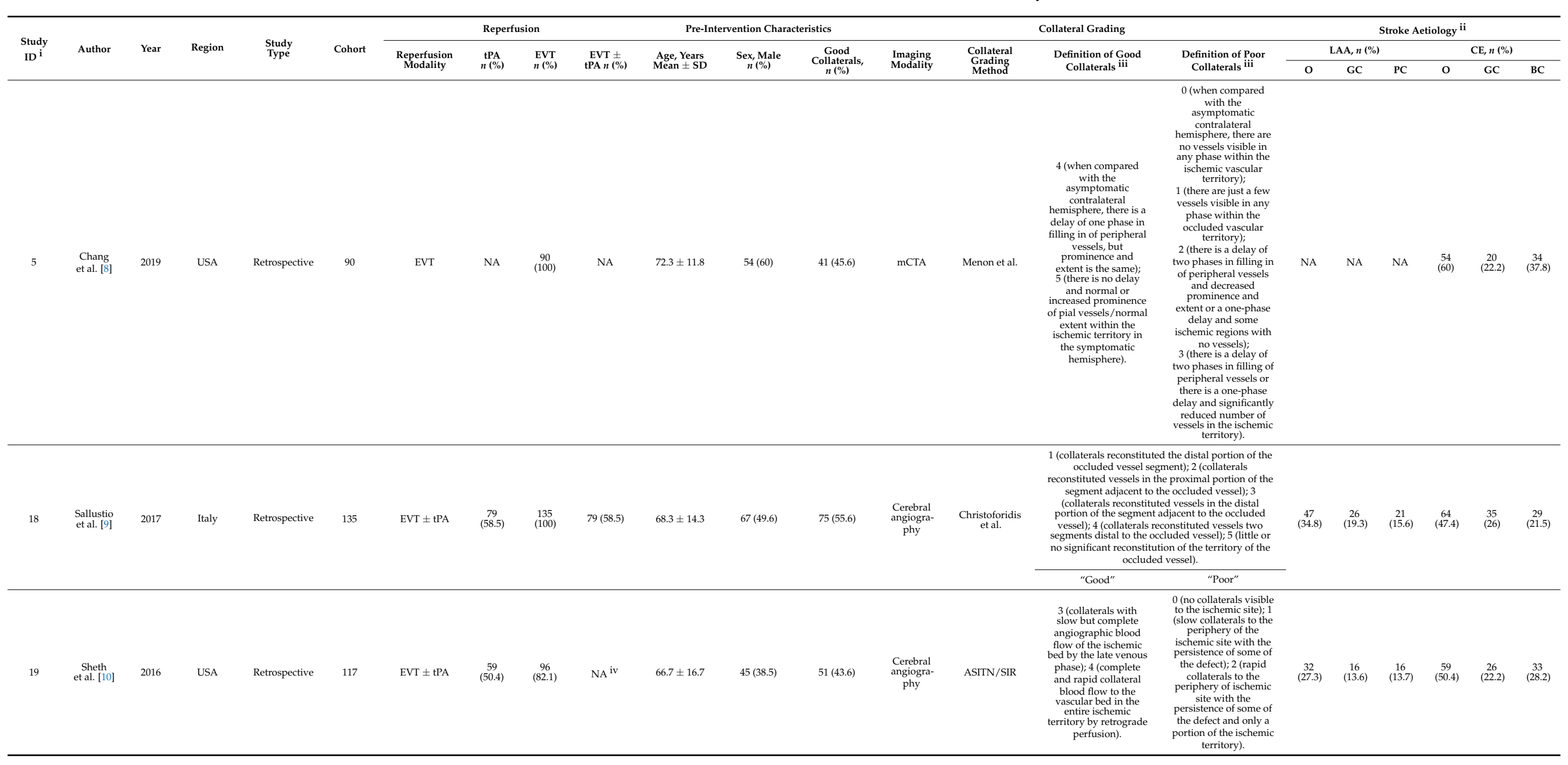


Table 1. Cont.

\begin{tabular}{|c|c|c|c|c|c|c|c|c|c|c|c|c|c|c|c|c|c|c|c|c|c|c|}
\hline \multirow{3}{*}{$\begin{array}{l}\text { Study } \\
\text { ID }^{\mathrm{i}}\end{array}$} & \multirow{3}{*}{ Author } & \multirow{3}{*}{ Year } & \multirow{3}{*}{ Region } & \multirow{3}{*}{$\begin{array}{l}\text { Study } \\
\text { Type }\end{array}$} & \multirow{3}{*}{ Cohort } & \multicolumn{4}{|c|}{ Reperfusion } & \multicolumn{3}{|c|}{ Pre-Intervention Characteristics } & \multicolumn{4}{|c|}{ Collateral Grading } & \multicolumn{6}{|c|}{ Stroke Aetiology ii } \\
\hline & & & & & & \multirow{2}{*}{$\begin{array}{c}\text { Reperfusion } \\
\text { Modality }\end{array}$} & \multirow{2}{*}{$\begin{array}{c}\mathrm{tPA} \\
n(\%) \\
\end{array}$} & \multirow{2}{*}{$\begin{array}{c}\mathrm{EVT} \\
n(\%) \\
n(n)\end{array}$} & \multirow{2}{*}{ 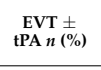 } & \multirow{2}{*}{$\begin{array}{c}\text { Age, Years } \\
\text { Mean } \pm \text { SD } \\
\end{array}$} & \multirow{2}{*}{$\begin{array}{c}\text { Sex, Male } \\
n(\%)\end{array}$} & \multirow{2}{*}{$\begin{array}{c}\text { Good } \\
\text { Collaterals, } \\
n(\%)\end{array}$} & \multirow{2}{*}{$\begin{array}{l}\text { Imaging } \\
\text { Modality }\end{array}$} & \multirow{2}{*}{$\begin{array}{l}\text { Collateral } \\
\text { Grading } \\
\text { Method } \\
\end{array}$} & \multirow{2}{*}{$\begin{array}{c}\text { Definition of Good } \\
\text { Collaterals iii }\end{array}$} & \multirow{2}{*}{$\begin{array}{c}\text { Definition of Poor } \\
\text { Collaterals iii }\end{array}$} & \multicolumn{3}{|c|}{ LAA, $n(\%)$} & \multicolumn{3}{|c|}{$\mathrm{CE}, n(\%)$} \\
\hline & & & & & & & & & & & & & & & & & $\mathrm{o}$ & GC & PC & $\mathrm{o}$ & GC & BC \\
\hline $22^{\mathrm{v}}$ & $\begin{array}{c}\text { Hwang } \\
\text { et al. [11] }\end{array}$ & 2015 & Korea & Retrospective & 207 & $\underset{\mathrm{vi}}{\mathrm{EVT} \pm \mathrm{tPA}}$ & $\begin{array}{l}103 \\
(49.8)\end{array}$ & $\underset{\text { vii }}{\mathrm{NA}}$ & $\mathrm{NA}$ vii & $67.1 \pm 11.1$ & $125(60.4)$ & $131(63.3)$ & $\begin{array}{l}\begin{array}{c}\text { Cerebral } \\
\text { angiogra- } \\
\text { phy }\end{array} \\
\text { phe }\end{array}$ & ASITN/SIR & 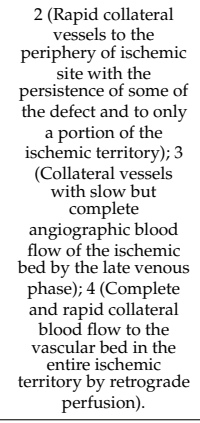 & $\begin{array}{l}\text { 0 (No collateral vessels } \\
\text { visible to the ischemic } \\
\text { site) } 1 \text { (Slow collateral } \\
\text { vessels to the } \\
\text { periphery of the } \\
\text { ischemic site with the } \\
\text { persistence of ome of } \\
\text { the defect). }\end{array}$ & $\begin{array}{l}66 \\
(31.9)\end{array}$ & $\begin{array}{l}40 \\
(19.3)\end{array}$ & $\begin{array}{l}26 \\
(12.6)\end{array}$ & $\begin{array}{l}107 \\
(51.7)\end{array}$ & $\begin{array}{c}68 \\
(32.8)\end{array}$ & $\begin{array}{l}39 \\
(18.8)\end{array}$ \\
\hline $31^{\mathrm{viii}}$ & $\begin{array}{l}\text { Asqui } \\
\text { Det al. [3] }\end{array}$ & 2020 & USA & Retrospective & 283 & $\mathrm{EVT} \pm \mathrm{PAA}$ & $\begin{array}{l}130 \\
(45.9)\end{array}$ & $\begin{array}{l}270 \\
(95.4)\end{array}$ & $\mathrm{NA}^{\mathrm{ix}}$ & $69.2 \pm 15.2$ & $159(56.2)$ & 129 (45.6) & SCTA & Miteff & $\begin{array}{l}\text { Good (major MCA } \\
\text { branches reconstituted } \\
\text { distal to the occlusion) }\end{array}$ & $\begin{array}{c}\text { moderate (some MCA } \\
\text { branches shown in the } \\
\text { Sylvian fissure); poor } \\
\text { (ynly distal superficial } \\
\text { MCA branches } \\
\text { reconstituted). }\end{array}$ & $\begin{array}{l}52 \\
(18.4)\end{array}$ & $\begin{array}{l}32 \\
(11.3)\end{array}$ & $\begin{array}{l}20 \\
(7.1)\end{array}$ & $\begin{array}{l}178 \\
(62.9)\end{array}$ & $\begin{array}{l}68 \\
(24)\end{array}$ & $\begin{array}{l}110 \\
(38.9)\end{array}$ \\
\hline 33 & $\begin{array}{l}\text { Hassser } \\
\text { et al. [12] }\end{array}$ & 2020 & Austria & Retrospective & 281 & $\mathrm{EVT} \pm \mathrm{tPA}$ & $\begin{array}{l}166 \\
(59.1)\end{array}$ & $\begin{array}{l}281 \\
(100)\end{array}$ & $166(59.1)$ & $68.6 \pm 12.1$ & $144(51.2)$ & $143(50.9)$ & $\begin{array}{l}\text { SCTA, } \\
\text { MRI }\end{array}$ & Tan & 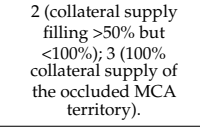 & $\begin{array}{l}0 \text { (absent collateral } \\
\text { supply of the affected } \\
\text { MCA territory); } 1 \\
\text { (collateral supply } \\
\text { filling } \leq 50 \% \text { ). }\end{array}$ & $\begin{array}{l}46 \\
(16.4)\end{array}$ & $\begin{array}{l}35 \\
(12.5)\end{array}$ & $\begin{array}{l}11 \\
(3.9)\end{array}$ & $\mathrm{NA}$ & $\mathrm{NA}$ & $\mathrm{NA}$ \\
\hline 39 & $\begin{array}{l}\text { Rebello } \\
\text { et al. [4] }\end{array}$ & 2017 & USA & Retrospective & 122 & $\mathrm{EVT} \pm \mathrm{tPA}$ & $\begin{array}{l}54 \\
(44.3)\end{array}$ & $\begin{array}{l}122 \\
(100)\end{array}$ & $54(44.3)$ & $69.7 \pm 12.9$ & $64(52.5)$ & $94(77)$ & sCTA & Souza et al. & $\begin{array}{c}2 \text { (diminished } \\
\text { collaterals in }<50 \% \text { of } \\
\text { the affected territoryy); } \\
3 \text { (collaterals equal to } \\
\text { the contralateral side); } \\
4 \text { (increased } \\
\text { collaterals). }\end{array}$ & $\begin{array}{c}0 \text { (absent collaterals in } \\
>50 \% \text { of the affected } \\
\text { territory); } 1 \\
\text { (diminished collaterals } \\
\text { in }>50 \% \text { of the affected } \\
\text { territory). }\end{array}$ & $\begin{array}{l}34 \\
(27.9)\end{array}$ & $\begin{array}{l}31 \\
(25.4)\end{array}$ & $\begin{array}{c}3 \\
(2.5)\end{array}$ & $\begin{array}{l}88 \\
(72.1)\end{array}$ & $\begin{array}{l}63 \\
(51.6)\end{array}$ & $\begin{array}{l}25 \\
(20.5)\end{array}$ \\
\hline
\end{tabular}

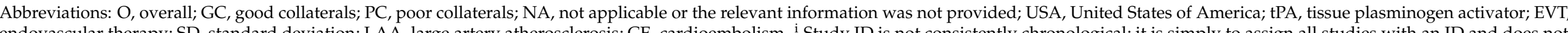

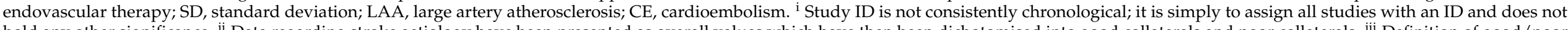

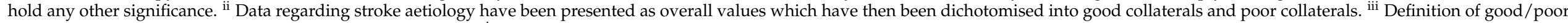

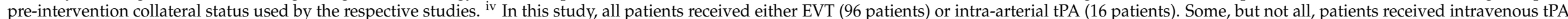

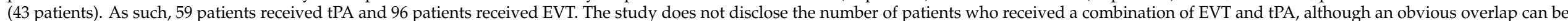

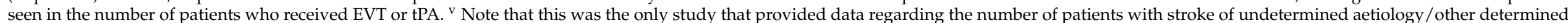

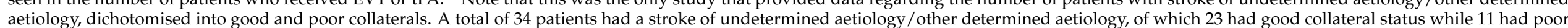

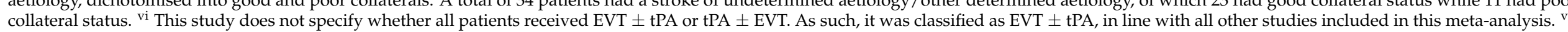

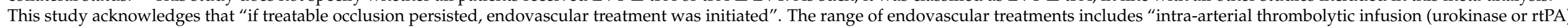

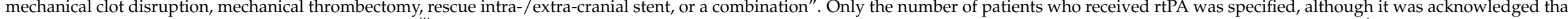

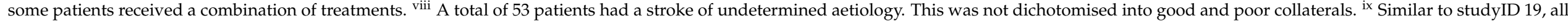

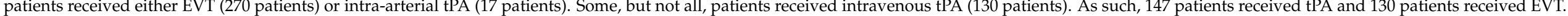
The study does not disclose the number of patients who received a combination of EVT and tPA, although an obvious overlap can be seen in the number of patients who received EVT or tPA. 


\subsection{Quality Assessment of Included Studies}

The modified Jadad analysis, a scoring system that analyses the methodology of a trial, was used to assess the quality of each included study [13,14]. The risk of funding bias was also assessed by analysing the sources of funding for each study $[15,16]$.

\subsection{Statistical Analysis}

All statistical analyses were performed using STATA (version 13.0, StataCorp LLC, College Station, TX, USA). The pre-intervention characteristics of patients were recorded and converted from median and interquartile range (IQR) to mean and standard deviation (SD), where applicable [17]. The association of stroke aetiologies, specifically LAA and $\mathrm{CE}$, with pre-intervention collateral status was investigated by performing a meta-analysis using DerSimonian and Laird random-effects modelling. Forest plots, containing summary effects for random-effects and inverse-variance weighted fixed-effect models, were generated to present the risk ratios (RR) (95\% confidence intervals [CI]), percentage weights and the between-studies heterogeneity ( $\mathrm{I}^{2}$ statistic, $p$-value). Additionally, summary effects and heterogeneity obtained from the meta-analysis (using the DerSimonian and Laird random-effects method, Mantel-Haenszel fixed-effect method and inverse-variance weighted fixed-effect) were also tabulated. An $\mathrm{I}^{2}$ of $75-100 \%$ is considerable, $50-90 \%$ is substantial, $30-60 \%$ is moderate and $0-40 \%$ is low heterogeneity, based on the Cochrane handbook [18]. The tests of overall effect drawn from the Z-test and $p$-values were also considered. The degree of inconsistency or heterogeneity across studies was quantified using the $\mathrm{I}^{2}$ index test and $p$-value. Other heterogeneity parameters including Cochran's $\mathrm{Q}$ (heterogeneity in effect sizes), $\mathrm{H}$ (relative excess in Cochran's $\mathrm{Q}$ over its degrees-of-freedom) and $\tau$ (heterogeneity variance estimate) test values obtained with the summary effects were also presented. Publication bias was assessed using funnel plots and Egger's test of effect sizes. Using the "metainf" STATA command, analysis was also performed by excluding one study at a time to study the effect of one study on the overall effect. This helped assess the impact of each included study on the meta-analysis (Supplemental Figure S1). A $p$-value of $<0.05$ was considered statistically significant.

\section{Results}

3.1. Description of Included Studies

A total of 7 studies were included in this study, with a cumulative cohort of 1235 patients [3,4,8-12]. Of these, 664 had good pre-intervention collateral status while 571 had poor pre-intervention collateral status. The mean age was 68.65 years $(S D=13.54)$. Pre-intervention systolic blood pressure was available for 419 patients, with a mean value of $143.6(\mathrm{SD}=29.69)$. The clinical characteristics of all included studies, as well as the clinical outcomes they assess, can be found in Table 1. Collateral grading methods, as well as the description of the corresponding grading system/s, are provided in Table 1 and Supplemental Table S4. Data regarding risk factors and aetiology and the prevalence of each of them have been provided in Table 2. Effect size analysis for LAA or CE can be found in Supplemental Figure S2. The Jaded analysis and funding bias scores of each of the included studies can be found in Supplemental Table S1. 
Table 2. Overall summary of the prevalence of risk factors and stroke aetiologies in the meta-analysis.

\begin{tabular}{ccc}
\hline Clinical Variable & Number of Patients with Data Available & Characteristics $\boldsymbol{n}$ (\%) \\
Atrial fibrillation & Risk Factors & $466(48.9)$ \\
Diabetes mellitus & 952 & $194(20.3)$ \\
Hyperlipidaemia & 952 & $232(28.4)$ \\
Hypertension & 817 & $654(67.7)$ \\
Coronary artery disease & 952 & $44(14.8)$ \\
Past stroke & 297 & $80(19.3)$ \\
Smoker & 414 & $198(20.8)$ \\
Cardio embolism & 952 & $277(24.2)$ \\
Undetermined & Aetiology & $550(57.7)$ \\
Small vessel disease & 1145 & $87(17.8)$ \\
\hline
\end{tabular}

The summary effects and heterogeneity obtained from all included studies can be found in Table 3.

Table 3. Summary effects and heterogeneity obtained from the meta-analysis of the association of pre-intervention collateral status with stroke aetiology.

\begin{tabular}{|c|c|c|c|c|c|c|c|c|c|c|c|c|c|}
\hline \multirow{3}{*}{ Outcome } & \multirow{3}{*}{$\begin{array}{l}\text { Effect } \\
\text { Measure }\end{array}$} & \multirow{3}{*}{$\begin{array}{l}\text { Treatment } \\
\text { Subgroup }\end{array}$} & \multicolumn{6}{|c|}{ Summary Effects } & \multirow{2}{*}{\multicolumn{4}{|c|}{ Heterogeneity $\mathbb{I}$}} & \multirow{3}{*}{$\begin{array}{c}\begin{array}{c}\text { Heterogeneity } \\
\text { Variance Estimates }\end{array} \\
\tau^{2 \dagger}\end{array}$} \\
\hline & & & \multicolumn{2}{|c|}{ REDL } & \multicolumn{2}{|c|}{ FEMH } & \multicolumn{2}{|c|}{ FEIV } & & & & & \\
\hline & & & $\begin{array}{c}\mathbf{R R} \\
(95 \% \mathrm{CI})\end{array}$ & $\begin{array}{c}\text { Tests of } \\
\text { Overall } \\
\text { Effect }\end{array}$ & $\begin{array}{c}\text { RR } \\
(95 \% \mathrm{CI})\end{array}$ & $\begin{array}{c}\text { Tests of } \\
\text { Overall } \\
\text { Effect }\end{array}$ & $\begin{array}{c}\mathrm{RR} \\
(95 \% \mathrm{CI})\end{array}$ & $\begin{array}{c}\text { Tests of } \\
\text { Overall } \\
\text { Effect }\end{array}$ & $\begin{array}{c}\text { Cochran's } \\
\text { Q }\end{array}$ & H & $I^{2 *}$ & $p$-Value & \\
\hline LAA & $\mathrm{RR}$ & $\mathrm{EVT} \pm \mathrm{tPA}$ & $\begin{array}{c}1.24 \\
(1.04-1.50)\end{array}$ & $\begin{array}{l}p=0.02 \\
\mathrm{z}=2.33\end{array}$ & $\begin{array}{c}1.23 \\
(1.11-1.36)\end{array}$ & $\begin{array}{c}p<0.0001 \\
\mathrm{z}=3.87\end{array}$ & $\begin{array}{c}1.27 \\
(1.15-1.39)\end{array}$ & $\begin{array}{c}p<0.0001 \\
\mathrm{z}=4.75\end{array}$ & 16.05 & 1.79 & 68.8 & 0.007 & 0.0346 \\
\hline $\mathrm{CE}$ & $\mathrm{RR}$ & $\mathrm{EVT} \pm \mathrm{tPA}$ & $\begin{array}{c}0.83 \\
(0.71-0.98)\end{array}$ & $\begin{array}{c}p=0.027 \\
\mathrm{z}=-2.213\end{array}$ & $\begin{array}{c}0.84 \\
(0.75-0.94)\end{array}$ & $\begin{array}{c}p=0.002 \\
\mathrm{z}=-3.149\end{array}$ & $\begin{array}{c}0.83 \\
(0.75-0.92)\end{array}$ & $\begin{array}{l}p<0.0001 \\
\mathrm{z}=-3.526\end{array}$ & 10.61 & 1.46 & 52.9 & 0.060 & 0.0198 \\
\hline
\end{tabular}

Abbreviations: LAA = Large Artery Atherosclerosis; CE = Cardioembolic; EVT = endovascular thrombectomy; tPA = transplasminogen activator; REDL $=$ DerSimonian and Laird random-effects method; FEMH = Mantel-Haenszel fixed-effect method; FEIV = inverse-variance weighted fixed-effect; $R R=$ Risk ratio; $Q=$ Heterogeneity measures were calculated from the data with confidence intervals based on Cochran's $\mathrm{Q}$ test; $\mathrm{H}$ = relative excess in Cochran's $\mathrm{Q}$ over its degrees-of-freedom; $\mathrm{I}^{2}=$ proportion of total variation in effect estimate due to between-study heterogeneity (based on Cochran's $Q$ test); $\tau^{2}=$ among-study variance to test the comparisons of heterogeneity among subgroups; NA, not available/applicable. ${ }^{*}$ Values of $\mathrm{I}^{2}$ are percentages. ${ }^{\mathbb{I}}$ Heterogeneity measures were calculated from the data with $95 \%$ confidence intervals based on Gamma (random effects) distribution for $\mathrm{Q} .{ }^{\dagger}$ Heterogeneity variance estimates (tau $\leq$ ) were derived from the DerSimonian and Laird method.

\subsection{Association of Large Artery Atherosclerosis with Pre-Intervention Collateral Status}

Six studies assessed the association of LAA with pre-intervention collateral status, with a cumulative cohort of 1145 patients. Random effects modelling revealed that LAA was significantly associated with increased rates of good collaterals at pre-intervention (RR $1.24 ; 95 \%$ CI 1.04-1.50; $p=0.020, z=2.33$ ) (Figure 2A). There was substantial heterogeneity amongst the included studies $\left(\mathrm{I}^{2}=68.8 \% ; p=0.007\right)$. Egger's test and visual inspection of a funnel plot suggested the presence of some publication bias (e-value $=0.387)($ Supplemental Figure S3A). 


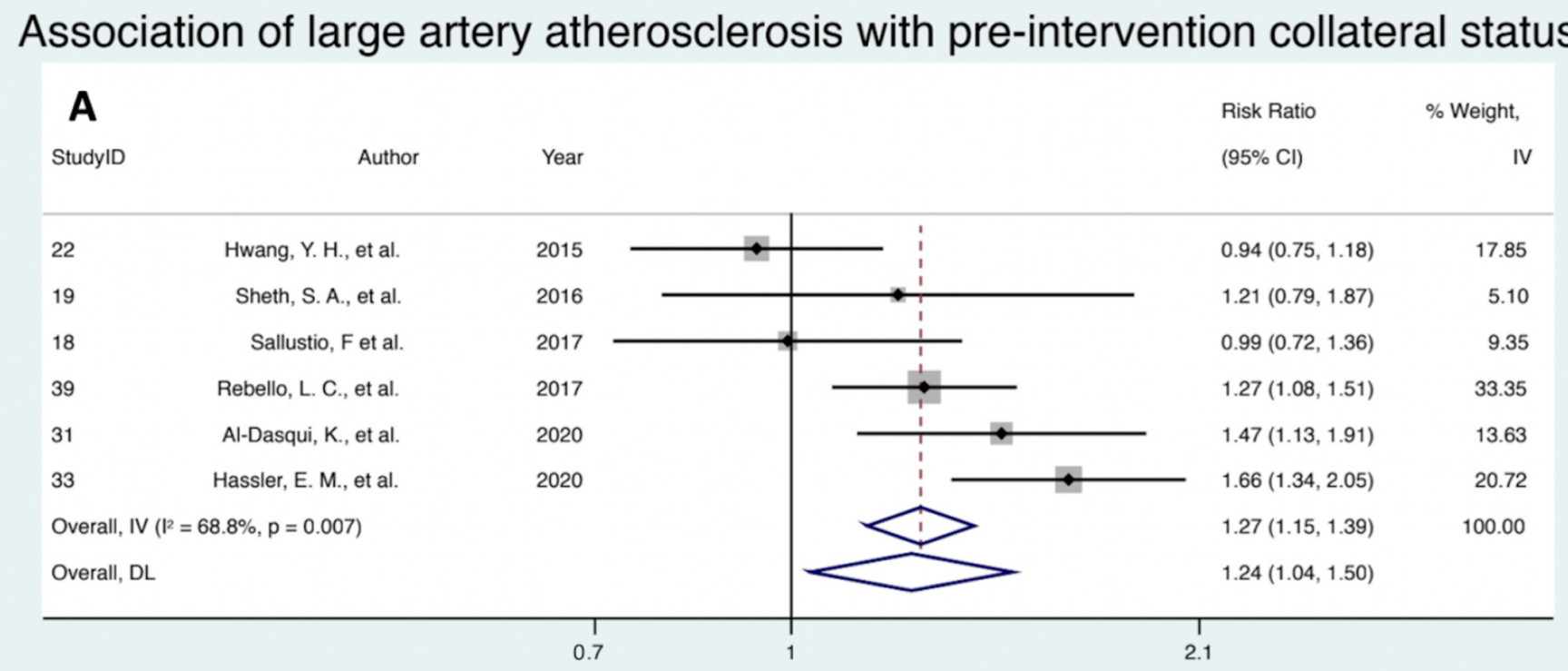

\section{Association of cardioembolism with pre-intervention collateral status}

B

\begin{tabular}{|c|c|c|c|c|c|}
\hline StudyID & Author & Year & & $(95 \% \mathrm{Cl})$ & IV \\
\hline 22 & Hwang, Y. H., et al. & 2015 & & $1.01(0.82,1.24)$ & 23.96 \\
\hline 19 & Sheth, S. A., et al. & 2016 & & $1.02(0.68,1.54)$ & 6.08 \\
\hline 18 & Sallustio, $\mathrm{F}$ et al. & 2017 & & $0.97(0.72,1.31)$ & 11.28 \\
\hline 39 & Rebello, L. C., et al. & 2017 & & $0.79(0.66,0.93)$ & 36.58 \\
\hline 5 & Chang JY., et al. & 2019 & & $0.63(0.41,0.99)$ & 5.24 \\
\hline 31 & Al-Dasqui, K., et al. & 2020 & & $0.66(0.51,0.84)$ & 16.86 \\
\hline \multicolumn{3}{|c|}{ Overall, IV $\left(I^{2}=52.9 \%, p=0.060\right)$} & & $0.83(0.75,0.92)$ & 100.00 \\
\hline \multicolumn{3}{|c|}{ Overall, DL } & & $0.83(0.71,0.98)$ & \\
\hline & & $\begin{array}{c}1 \\
0.45\end{array}$ & & & \\
\hline
\end{tabular}

Figure 2. Forest plot showing the association of (A) large artery atherosclerosis stroke aetiology and (B) cardioembolism stroke aetiology with the pre-intervention collateral status in acute ischemic stroke patients receiving reperfusion therapy. Note: Random effect modelling (DL) values were used. Abbreviations: CI, confidence interval; IV, inverse variance; DL, DerSimonian and Laird.

\subsection{Association of Cardioembolism with Pre-Intervention Collateral Status}

Six studies with a cumulative cohort of 954 patients investigated the association of CE and pre-intervention collateral status. Random effects modelling demonstrated that CE was associated significantly with increased rates of poor collaterals (RR 0.83; 95\% CI 0.71-0.98; $p=0.027, \mathrm{z}=-2.213$ ) (Figure $2 \mathrm{~B}$ ). There was moderate to substantial heterogeneity amongst the included studies $\left(\mathrm{I}^{2}=52.9 \% ; p=0.06\right)$. Egger's test and visual inspection of a funnel plot suggested the presence of little to no publication bias (e-value $=0.629)$ (Supplemental Figure S3B).

\section{Discussion}

The results of this meta-analysis indicated that stroke aetiology was associated significantly with pre-intervention cerebral collateral status in AIS patients undergoing RT. Specifically, LAA was associated significantly with increased rates of good pre-intervention collaterals; whilst CE strokes were associated significantly with increased rates of poor 
pre-intervention collaterals. Collateral status in AIS is an important factor that has a role in mediating outcomes after RT [1,19]. Whilst previous meta-analyses have tried to analyse collateral status as a predictor of outcome in endovascular treatment of stroke [20,21]; to our knowledge, this is the first work to attempt to meta-analyse the association of collateral status with stroke aetiology.

The formation of cerebral collaterals can be affected by several environmental factors with the main factor in question relating to the presence of atherosclerotic plaques which obstruct cerebral blood flow. Plaques such as these alter haemodynamics within cerebral vessels, increasing shear pressure, thus activating endothelial cells and downstream signal transduction pathways, which contribute to the formation of collaterals and vascular remodelling [5]. This pathophysiological mechanism is responsible for the findings in a study by Rebello et al. wherein AIS patients with cervical atherosclerotic steno-occlusive disease had favourable pre-intervention collateral status when compared to those who experienced an embolic stroke, secondary to atrial fibrillation [4]. This association is also supported by Hassler et al. who noted that a pre-existing atherosclerotic extracranial ipsilateral carotid artery stenosis of $\geq 50 \%$ was associated with better collateral status [12]. This is consistent with the results of this meta-analysis wherein LAA was significantly associated with pre-intervention collateral status in AIS patients.

Stroke aetiology may mediate collateral recruitment-potentially influencing response to time-critical reperfusion therapies in AIS [22]. This meta-analysis did not investigate this aspect. We postulate that in LAA patients, better collaterals develop over time in a proportion of patients resulting in high-grade stenosis [22]. Currently, data on whether stroke aetiology impacts reperfusion and outcomes after reperfusion therapy in AIS patients with large vessel occlusion in the anterior circulation, especially those treated with EVT or combined therapies (EVT \pm IVT), are limited $[23,24]$. However, previous studies have shown that CE patients have worse outcomes than LAA patients $[22,25,26]$, presumably due to greater successful reperfusion rates $[25,26]$. However, other studies found no statistically significant difference in successful reperfusion rates between LAA and CE, despite higher rates of favourable 3-month functional outcomes, post-reperfusion, for LAA [22-24]. Notably, in other studies, successful reperfusion is potentially more important for better outcomes and, specifically, more so in CE strokes than in the LAA [27]. It is worth noting that heart failure is more prevalent in stroke with CE than LAA, which may also contribute to poorer outcomes in the CE subgroup [28].

With regards to outcomes in AIS patients with CE aetiology, a recent study showed atrial fibrillation was associated with symptomatic intracerebral haemorrhage (sICH) in AIS patients treated with IVT [29]. This could be explained by the presence of poor collaterals in AF patients, or in AIS patients with CE aetiology, leading to an increased risk of sICH after reperfusion. A meta-analysis by Lu et al. about the safety and efficacy of IVT for AIS patients with AF and found worse outcomes in AIS patients with AF than those without AF. Authors also reported a higher incidence of sICH in AF patients than in non-AF patients ( $6.4 \%$ vs. $4.1 \% ; p<0.001)$, as well as in AF patients receiving IVT compared to AF patients not receiving IVT $(5.7 \%$ vs. $1.6 \% ; p<0.001)$ [30].

As opposed to the chronic cerebral hypoperfusion induced collateral formation in LAA, the mechanism through which CE causes ischaemia is short-term and does not allow for collateral formation or vascular remodelling [5]. AIS patients with CE as their stroke aetiology are less likely to experience the benefits of good collateral supply. This is also seen in findings noted by Rebello et al., wherein AIS patients with underlying CE as their stroke aetiology do not associate with favourable pre-intervention collateral status [4]. Patients with CE are less likely to have good pre-intervention collateral status compared to those with LAA. It is worth noting that in stroke patients with intracranial atherosclerotic disease, concomitant systemic atherosclerosis (involving other arteries such as the extracranial carotid, coronary, aorta and lower extremity peripheral arteries) and overlapping stroke aetiologies, though less well studied [31], are not infrequent in clinical settings [32]. Hence, good collaterals may be observed in patients with embolic aetiology and co-existing LAA. 
Another factor that has been shown to associate with pre-intervention collateral status is perilesional hyperperfusion (PLH). A prospective cohort found an independent association of PLH with good pre-intervention collateral status as well as major reperfusion at $24 \mathrm{~h}$ [19]. Pre-intervention collateral status was found to accurately predict PLH patterns, indicating an indirect role of PLH in prognosis [19]. The study also found that AIS patients with PLH were eight times more likely to experience HT when compared to patients without PLH [19]. The recruitment of immune cells following an ischemic event may be a contributing factor to this association [33]. This study used arterial spin labelling (ASL) to characterise PLH, demonstrating how advanced imaging, such as computed tomography perfusion (CTP) [34,35], CT angiography (CTA) [36] and ASL [19], have allowed quantitative estimation and characterisation of cerebral perfusion and the delineation of angiographic features including collateral status in AIS patients [14,16].

Multiphase CT angiography (mCTA) plays an important role in the localisation of occlusion as well as in the evaluation of spatial and temporal profile of the collateral status and its patency $[1,37]$. Rapid assessment of collateral circulation downstream of occlusion is of value in the selection of candidates for EVT [38]. Whilst qualitative scoring scales of collateral assessment are commonly used, they are limited due to complex method which may be time- and skill-intensive and their broader use is limited due to the lack of a standardised method [1,39]. Verdolotti et al. developed a simpler tool, Colorviz, which could be useful in the immediate evaluation of collaterals with comparable diagnostic evaluation to the mCTA. This could especially be useful for less experienced raters/clinicians [40].

Inflammatory cells play a crucial role in collaterogenesis, due to their ability to produce metalloproteinases and growth factors [5,41,42]. They are involved also in the formation of atherosclerotic plaques, thus highlighting their role in LAA strokes [43]. Semerano et al. found that lymphopenia and a high neutrophil-lymphocyte ratio (NLR), following an AIS, have been linked to poor clinical outcomes, especially in patients with good pre-intervention collateral status and successful reperfusion [33]. A higher neutrophil count one day after hospital admission was associated with sICH while a higher NLR was associated with parenchymal haemorrhage and $\mathrm{sICH}$ [33]. We postulate that the progression to poor outcomes despite good collateral status and successful reperfusion, e.g., in AIS patients with LAA, may be explained by other factors such as NLR [42] and severity of leukoaraiosis [44,45].

There are several limitations within the current study. A large majority of the included studies were retrospective, cross-sectional studies that provided a lower quality of evidence when compared to randomised clinical trials. However, since this current meta-analysis is not an investigation of outcomes, and since the specific research question of the association of stroke aetiology with collateral status is purely observational, it is not possible to answer this specific question. There were several limitations regarding the assessment of collateral status: single-phase computed tomography angiography is the most widely used imaging modality to assess collateral status. Due to its ability to visualise collaterals at a single point in time, it may not capture all collaterals that are present, thus underestimating the pre-intervention collateral status. The lack of a standardised grading system to assess collateral status is a source of heterogeneity that further impacts the reliability of the available data. Most of the included studies have used different grading methods (Table 1), which leads to inconsistencies in the objective definition of good versus poor collateral status. Further contributing to this limitation is the potential bias involved in the process of manually grading collaterals. Additionally, the different methods used to assess aetiology (such as TOAST or CCS) is another source of heterogeneity. Therefore, the findings of this meta-analysis should be interpreted in the context of study design and study population, limiting its generalisability to other study populations. The substantial heterogeneity amongst studies investigating the association of stroke aetiology with collateral status is also a limitation. Some studies included patients with a mixture of stroke aetiologies. However, given that groupwise data on collateral status were only available for CE and LAA aetiologies, the current study focused on these two specific aetiologies. Groupwise 
data on cryptogenic stroke and collateral status were not sufficient to merit inclusion in this current meta-analysis. Moreover, CE and LAA contribute to a majority of AIS patients in a real-world setting, therefore, this information can be of value in clinical practice. Moreover, we also acknowledge that some of these subgroups could have overlapping aetiologies, e.g., in Hassler et al. [12], 46 LAA subjects were only characterised by the presence of carotid artery stenosis but, among them, there were patients affected by atrial fibrillation, so they could be affected by cardioembolic strokes or, according to the TOAST classification, by strokes from an undetermined cause. Besides, given the varying pathogenesis of atherosclerotic occlusion based on the site of occlusion and heterogenous intervention protocols, it may be useful to compare LAA with CE for AIS with the same occlusion site [22].

Given that the random-effects model was used in the meta-analysis, some of these effects potentially would have been mitigated. There is a shortage of primary studies addressing the association between stroke aetiology and pre-intervention collateral status, thus limiting its evidence-based incorporation into clinical practice. Further high-quality studies are required to validate the findings of the present study. Future studies should aim to reduce heterogeneity associated with collateral grading methods and aetiology assessment tools as a means of improving the clinical applicability of their results.

In conclusion, stroke aetiology is significantly associated with pre-intervention collateral status in AIS patients receiving RT. This meta-analysis also demonstrates that LAA is significantly associated with increased rates of good collaterals and $\mathrm{CE}$ with increased rates of poor collaterals. Despite limited primary studies, to the best of our knowledge, this is the first meta-analysis to investigate the association of stroke aetiology with pre-intervention collateral status. Gaining a better understanding of the association of stroke aetiology with pre-intervention collateral status may assist in the evaluation and management of AIS patients undergoing RT.

Supplementary Materials: The following are available online at https: / www.mdpi.com/article/ 10.3390/neurolint13040060/s1, Figure S1: Influence of a single study in meta-analysis estimation: (a) large artery atherosclerosis, (b) cardioembolism, Figure S2: Effect size analysis of all studies assessing the association between baseline collateral status and large artery atherosclerosis as an aetiology of stroke, Figure S3: Funnel plot displaying publication bias amongst all studies investigating the association of stroke aetiologies, (A) large artery atherosclerosis and (B) cardioemobolism, with pre-intervention collateral status, Table S1: Modified Jadad analysis scores and funding bias scores for each of the included studies, Table S2: STARD-2015 checklist, Table S3: MOOSE checklist for meta-analyses of observational Studies, Table S4: Description of the main baseline cerebral collaterals grading scales used by the included studies.

Author Contributions: S.M.M.B. conceptualised the study, contributed to the planning, drafting and revision of the manuscript and supervised student work; S.M.M.B. encouraged A.S. to investigate and supervised the findings of this work. A.S. and S.M.M.B. wrote the first draft of this paper and were involved in data extraction and analyses. P.S., R.G.B., Z.C. and M.C.K. contributed to the writing, intellectual discussion and critical revision of the manuscript. All authors contributed to the revision of the manuscript. All authors have read and agreed to the published version of the manuscript.

Funding: Funding for the NSW Brain Clot Bank (Chief Investigator: S.M.M.B.) from the NSW Ministry of Health (2019-2022) is acknowledged. The funding body had no role in the study design, data collection, analysis, interpretation of findings or manuscript preparation. The content is solely the responsibility of the authors and does not necessarily represent the official views of the affiliated/funding organisation/s.

Institutional Review Board Statement: Not applicable (all analyses were based on previously published studies; thus, no ethical approval was required).

Informed Consent Statement: Not applicable.

Data Availability Statement: The original contributions presented in the study are included in the article/Supplementary Information, further inquiries can be directed to the corresponding author. 
Conflicts of Interest: The authors declare that they have no conflicts of interest.

\section{References}

1. Ravindran, A.V.; Killingsworth, M.C.; Bhaskar, S. Cerebral collaterals in acute ischaemia: Implications for acute ischaemic stroke patients receiving reperfusion therapy. Eur. J. Neurosci. 2021, 53, 1238-1261. [CrossRef] [PubMed]

2. Bang, O.Y.; Saver, J.L.; Alger, J.R.; Starkman, S.; Ovbiagele, B.; Liebeskind, D.S.; Investigators, U.C. Determinants of the distribution and severity of hypoperfusion in patients with ischemic stroke. Neurology 2008, 71, 1804-1811. [CrossRef] [PubMed]

3. Al-Dasuqi, K.; Payabvash, S.; Torres-Flores, G.A.; Strander, S.M.; Nguyen, C.K.; Peshwe, K.U.; Kodali, S.; Silverman, A.; Malhotra, A.; Johnson, M.H.; et al. Effects of Collateral Status on Infarct Distribution Following Endovascular Therapy in Large Vessel Occlusion Stroke. Stroke 2020, 51, e193-e202. [CrossRef] [PubMed]

4. Rebello, L.C.; Bouslama, M.; Haussen, D.C.; Grossberg, J.A.; Dehkharghani, S.; Anderson, A.; Belagaje, S.R.; Bianchi, N.A.; Grigoryan, M.; Frankel, M.R.; et al. Stroke etiology and collaterals: Atheroembolic strokes have greater collateral recruitment than cardioembolic strokes. Eur. J. Neurol. 2017, 24, 762-767. [CrossRef] [PubMed]

5. Helisch, A.; Schaper, W. Arteriogenesis: The development and growth of collateral arteries. Microcirculation $2003,10,83-97$. [CrossRef]

6. Marnane, M.; Duggan, C.A.; Sheehan, O.C.; Merwick, A.; Hannon, N.; Curtin, D.; Harris, D.; Williams, E.B.; Horgan, G.; Kyne, L.; et al. Stroke subtype classification to mechanism-specific and undetermined categories by TOAST, A-S-C-O, and causative classification system: Direct comparison in the North Dublin population stroke study. Stroke 2010, 41, 1579-1586. [CrossRef]

7. Stroup, D.F.; Berlin, J.A.; Morton, S.C.; Olkin, I.; Williamson, G.D.; Rennie, D.; Moher, D.; Becker, B.J.; Sipe, T.A.; Thacker, S.B. Meta-analysis of observational studies in epidemiology: A proposal for reporting. Meta-analysis Of Observational Studies in Epidemiology (MOOSE) group. JAMA 2000, 283, 2008-2012. [CrossRef]

8. Chang, J.Y.; Jeon, S.B.; Jung, C.; Gwak, D.S.; Han, M.K. Postreperfusion Blood Pressure Variability After Endovascular Thrombectomy Affects Outcomes in Acute Ischemic Stroke Patients With Poor Collateral Circulation. Front. Neurol. 2019, 10, 346. [CrossRef]

9. Sallustio, F.; Motta, C.; Pizzuto, S.; Diomedi, M.; Giordano, A.; D’Agostino, V.C.; Sama, D.; Mangiafico, S.; Saia, V.; Legramante, J.M.; et al. CT angiography-based collateral flow and time to reperfusion are strong predictors of outcome in endovascular treatment of patients with stroke. J. Neurointerv. Surg. 2017, 9, 940-943. [CrossRef]

10. Sheth, S.A.; Sanossian, N.; Hao, Q.; Starkman, S.; Ali, L.K.; Kim, D.; Gonzalez, N.R.; Tateshima, S.; Jahan, R.; Duckwiler, G.R.; et al Collateral flow as causative of good outcomes in endovascular stroke therapy. J. Neurointerv. Surg. 2016, 8, 2-7. [CrossRef]

11. Hwang, Y.H.; Kang, D.H.; Kim, Y.W.; Kim, Y.S.; Park, S.P.; Liebeskind, D.S. Impact of time-to-reperfusion on outcome in patients with poor collaterals. Am. J. Neuroradiol. 2015, 36, 495-500. [CrossRef]

12. Hassler, E.; Kneihsl, M.; Deutschmann, H.; Hinteregger, N.; Magyar, M.; Wiesspeiner, U.; Haidegger, M.; Fandler-Hofler, S.; Eppinger, S.; Niederkorn, K.; et al. Relationship between stroke etiology and collateral status in anterior circulation large vessel occlusion. J. Neurol. 2020, 267, 3362-3370. [CrossRef] [PubMed]

13. Shen, Y.-W.; Zhang, X.-M.; Lv, M.; Chen, L.; Qin, T.-J.; Wang, F.; Yang, J.; Liu, P.-J.; Yang, J. Utility of gonadotropin-releasing hormone agonists for prevention of chemotherapy-induced ovarian damage in premenopausal women with breast cancer: A systematic review and meta-analysis. Onco Targets Ther. 2015, 8, 3349-3359. [CrossRef] [PubMed]

14. Katyal, A.; Calic, Z.; Killingsworth, M.; Bhaskar, S.M.M. Diagnostic and prognostic utility of computed tomography perfusion imaging in posterior circulation acute ischemic stroke: A systematic review and meta-analysis. Eur. J. Neurol. 2021, 28, 2657-2668. [CrossRef]

15. Saunders, R.; Struys, M.; Pollock, R.F.; Mestek, M.; Lightdale, J.R. Patient safety during procedural sedation using capnography monitoring: A systematic review and meta-analysis. BMJ Open 2017, 7, e013402. [CrossRef] [PubMed]

16. Shi, C.; Killingsworth, M.C.; Bhaskar, S.M.M. Prognostic capacity of hyperdense middle cerebral artery sign in anterior circulation acute ischaemic stroke patients receiving reperfusion therapy: A systematic review and meta-analysis. Acta Neurol. Belg. 2021, 498. [CrossRef] [PubMed]

17. Wan, X.; Wang, W.; Liu, J.; Tong, T. Estimating the sample mean and standard deviation from the sample size, median, range and/or interquartile range. BMC Med. Res. Methodol. 2014, 14, 135. [CrossRef]

18. Douglas, D.A.A.; Birks, J.; Borenstein, M.; Campbell, M.; Deeks, J.; Egger, M.; Higgins, J.; Lau, J.; O’Rourke, K.; Rücker, G.; et al. Cochrane Handbook for Systematic Reviews of Interventions Version 6.2; Jonathan, J.P.H.J.D., Altman, D.G., Eds.; John Wiley \& Sons: Chichester, UK, 2021.

19. Bhaskar, S.; Bivard, A.; Stanwell, P.; Parsons, M.; Attia, J.R.; Nilsson, M.; Levi, C. Baseline collateral status and infarct topography in post-ischaemic perilesional hyperperfusion: An arterial spin labelling study. J. Cereb. Blood Flow Metab. 2017, 37, 1148-1162. [CrossRef]

20. Leng, X.; Fang, H.; Leung, T.W.; Mao, C.; Xu, Y.; Miao, Z.; Liu, L.; Wong, K.S.; Liebeskind, D.S. Impact of Collateral Status on Successful Revascularization in Endovascular Treatment: A Systematic Review and Meta-Analysis. Cerebrovasc. Dis. 2016, 41, 27-34. [CrossRef]

21. Qian, J.; Fan, L.; Zhang, W.; Wang, J.; Qiu, J.; Wang, Y. A meta-analysis of collateral status and outcomes of mechanical thrombectomy. Acta Neurol. Scand. 2020, 142, 191-199. [CrossRef] 
22. Zotter, M.; Piechowiak, E.I.; Balasubramaniam, R.; Von Martial, R.; Genceviciute, K.; Blanquet, M.; Slavova, N.; Sarikaya, H.; Arnold, M.; Gralla, J.; et al. Endovascular therapy in patients with large vessel occlusion due to cardioembolism versus large-artery atherosclerosis. Ther. Adv. Neurol. Disord. 2021, 14. [CrossRef]

23. Sun, B.; Shi, Z.; Pu, J.; Yang, S.; Wang, H.; Yang, D.; Hao, Y.; Lin, M.; Ke, W.; Liu, W.; et al. Effects of mechanical thrombectomy for acute stroke patients with etiology of large artery atherosclerosis. J. Neurol. Sci. 2019, 396, 178-183. [CrossRef] [PubMed]

24. Giray, S.; Ozdemir, O.; Baş, D.F.; İnanç, Y.; Arlıer, Z.; Kocaturk, O. Does stroke etiology play a role in predicting outcome of acute stroke patients who underwent endovascular treatment with stent retrievers? J. Neurol. Sci. 2017, 372, 104-109. [CrossRef] [PubMed]

25. Guglielmi, V.; LeCouffe, N.E.; Zinkstok, S.M.; Compagne, K.C.J.; Eker, R.; Treurniet, K.M.; Tolhuisen, M.L.; van der Worp, H.B.; Jansen, I.G.H.; van Oostenbrugge, R.J.; et al. Collateral Circulation and Outcome in Atherosclerotic Versus Cardioembolic Cerebral Large Vessel Occlusion. Stroke 2019, 50, 3360-3368. [CrossRef] [PubMed]

26. Schulz, U.G.; Rothwell, P.M. Differences in vascular risk factors between etiological subtypes of ischemic stroke: Importance of population-based studies. Stroke 2003, 34, 2050-2059. [CrossRef]

27. Rha, J.H.; Saver, J.L. The impact of recanalization on ischemic stroke outcome: A meta-analysis. Stroke 2007, 38, 967-973. [CrossRef]

28. Savarese, G.; Lund, L.H. Global Public Health Burden of Heart Failure. Card. Fail. Rev. 2017, 3, 7-11. [CrossRef]

29. Guo, H.; Xu, W.; Zhang, X.; Zhang, S.; Dai, Z.; Li, S.; Xie, Y.; Li, Y.; Xue, J.; Liu, X. A Nomogram to Predict Symptomatic Intracranial Hemorrhage After Intravenous Thrombolysis in Chinese Patients. Neuropsychiatr. Dis. Treat. 2021, 17, 2183-2190. [CrossRef]

30. $\mathrm{Hu}, \mathrm{Y}$; ; Ji, C. Efficacy and safety of thrombolysis for acute ischemic stroke with atrial fibrillation: A meta-analysis. BMC Neurol. 2021, 21, 66. [CrossRef]

31. Bhatt, D.L.; Steg, P.G.; Ohman, E.M.; Hirsch, A.T.; Ikeda, Y.; Mas, J.L.; Goto, S.; Liau, C.S.; Richard, A.J.; Röther, J.; et al. International prevalence, recognition, and treatment of cardiovascular risk factors in outpatients with atherothrombosis. JAMA 2006, 295, 180-189. [CrossRef]

32. Hoshino, T.; Sissani, L.; Labreuche, J.; Ducrocq, G.; Lavallée, P.C.; Meseguer, E.; Guidoux, C.; Cabrejo, L.; Hobeanu, C.; GongoraRivera, F.; et al. Prevalence of Systemic Atherosclerosis Burdens and Overlapping Stroke Etiologies and Their Associations With Long-term Vascular Prognosis in Stroke With Intracranial Atherosclerotic Disease. JAMA Neurol. 2018, 75, 203-211. [CrossRef] [PubMed]

33. Semerano, A.; Laredo, C.; Zhao, Y.; Rudilosso, S.; Renu, A.; Llull, L.; Amaro, S.; Obach, V.; Planas, A.M.; Urra, X.; et al. Leukocytes, Collateral Circulation, and Reperfusion in Ischemic Stroke Patients Treated With Mechanical Thrombectomy. Stroke 2019, 50, 3456-3464. [CrossRef] [PubMed]

34. Katyal, A.; Bhaskar, S. CTP-guided reperfusion therapy in acute ischemic stroke: A meta-analysis. Acta Neurol. Scand. 2021, 143, 355-366. [CrossRef] [PubMed]

35. Alexandre, A.M.; Pedicelli, A.; Valente, I.; Scarcia, L.; Giubbolini, F.; D'Argento, F.; Lozupone, E.; Distefano, M.; Pilato, F.; Colosimo, C. May endovascular thrombectomy without CT perfusion improve clinical outcome? Clin. Neurol. Neurosurg. 2020, 198, 106207. [CrossRef]

36. Bhaskar, S.; Bivard, A.; Parsons, M.; Nilsson, M.; Attia, J.R.; Stanwell, P.; Levi, C. Delay of late-venous phase cortical vein filling in acute ischemic stroke patients: Associations with collateral status. J. Cereb. Blood Flow Metab. 2017, 37, 671-682. [CrossRef]

37. Shaban, S.; Huasen, B.; Haridas, A.; Killingsworth, M.; Worthington, J.; Jabbour, P.; Bhaskar, S.M.M. Digital subtraction angiography in cerebrovascular disease: Current practice and perspectives on diagnosis, acute treatment and prognosis. Acta Neurol. Belg. 2021. [CrossRef]

38. Anadani, M.; Finitsis, S.; Clarençon, F.; Richard, S.; Marnat, G.; Bourcier, R.; Sibon, I.; Dargazanli, C.; Arquizan, C.; Blanc, R.; et al. Collateral status reperfusion and outcomes after endovascular therapy: Insight from the Endovascular Treatment in Ischemic Stroke (ETIS) Registry. J. Neurointerv. Surg. 2021. [CrossRef]

39. Smith, A.G.; Rowland Hill, C. Imaging assessment of acute ischaemic stroke: A review of radiological methods. Br. J. Radiol. 2018, 91, 20170573. [CrossRef]

40. Verdolotti, T.; Pilato, F.; Cottonaro, S.; Monelli, E.; Giordano, C.; Guadalupi, P.; Benenati, M.; Ramaglia, A.; Costantini, A.M.; Alexandre, A.; et al. ColorViz, a New and Rapid Tool for Assessing Collateral Circulation during Stroke. Brain Sci. 2020, 10, 882. [CrossRef]

41. Buschmann, I.; Schaper, W. The pathophysiology of the collateral circulation (arteriogenesis). J. Pathol. 2000, 190, 338-342. [CrossRef]

42. Sharma, D.; Spring, K.J.; Bhaskar, S.M.M. Neutrophil-lymphocyte ratio in acute ischemic stroke: Immunopathology, management, and prognosis. Acta Neurol. Scand. 2021, 144, 486-499. [CrossRef] [PubMed]

43. Kim, J.Y.; Park, J.; Chang, J.Y.; Kim, S.H.; Lee, J.E. Inflammation after Ischemic Stroke: The Role of Leukocytes and Glial Cells. Exp. Neurobiol. 2016, 25, 241-251. [CrossRef] [PubMed]

44. Rastogi, A.; Weissert, R.; Bhaskar, S.M.M. Leukoaraiosis severity and post-reperfusion outcomes in acute ischaemic stroke: A meta-analysis. Acta Neurol. Scand. 2021. [CrossRef] [PubMed]

45. Rastogi, A.; Weissert, R.; Bhaskar, S.M.M. Emerging role of white matter lesions in cerebrovascular disease. Eur. J. Neurosci. 2021, 54, 5531-5559. [CrossRef] [PubMed] 